\title{
Comparative Study on Visualizing Vector Graphics in WebGIS Applications with SVG and Flash Technologies
}

\author{
M. Li \\ School of Computer \\ South China Normal University \\ Guangzhou, China
}

\author{
X.H. Yang, Q.W. Chen, G. Li \\ Land and Resources Information and Technical Center \\ Guiyang, China
}

\author{
Y. Cao, J.Q. Zhang, H. Li \\ School of Computer \\ South China Normal University \\ Guangzhou, China
}

\begin{abstract}
This paper compared the performance of SVG and Flash when applied in WebGIS from different aspects, including basic characteristics, data storage, page rendering speed, interactivity etc. Through experiments and analysis, the result shows that: SVG and Flash can be used for visualizing WebGIS vector graphics. They are similar but have different characteristics. SVG, which is based on XML, has advantages in data exchange, transmission, integration and interoperability, it can be modified conveniently with low production cost. Flash has the advantage in terms of network animation, moreover, has high data compression, fast transmission and rendering speed. Finally, recommendations were made about how to choose vector map format in WebGIS.
\end{abstract} map

Keywords-SVG; flash; webgis; performance comparison; vector

\section{INTRODUCTION}

WebGIS (Web Geographic Information System) is a product of the combination of Internet and geographic information system. Its rapid development has greatly promoted the application of GIS(Geographic Information System), and it plays an important role in every aspect of reality, such as the design and construction of landslide warning system based on WebGIS [1], agricultural expert system based on WebGIS [2] etc. WebGIS is in deep development stage in both theory and application [3]. The traditional raster map is very inconvenient because of large transmission quantity of data, high bandwidth required, inefficient, poor quality in displaying and distortion when amplified [4]. The development and application of vector map data provides another solution. Vector graphics is very suitable for recording simple graphics such as symbols, icons and others.

We can name several technologies for displaying 2D vector graphics on the web however, two names rises among other contenders. These are the Macromedia's Shock Wave Flash (SWF) and the World Wide Web Consortium's (W3C) Scalable Vector Graphics (SVG). Flash is a mainstream format in WebGIS vector graphics publishing, while SVG is a new format. Especially in HTML5, SVG elements are seamlessly combined.

Flash is the criteria of the interactive vector graphics and Web cartoons launched by the Adobe (formerly Macromedia) company. SWF (Shock Wave Flash) is a dedicated output format for Flash. Coordinating with the ActionScript scripting language, Flash can well demonstrate the spatial data. Along with the launching of Flash API(Application Programming Interface)for browsing maps by ESRI(Environmental Systems Research Institute), Google, Baidu and other large companies in succession, the development of WebGIS based on Flash was of great concern [5], such as the application and development of WebGIS based on Flash [7], the construction of WebGIS based on Flash platform [8] etc.

SVG (Scalable Vector Graphics) is based on XML (Extensible Markup Language) and it is a graphic format used in description of two-dimensional vector graphics. SVG is not only an image format. Based on XML, SVG has inherited the characteristics of cross platform compatibility and scalability of XML that make high reusability. SVG elements can be embedded in other XML documents, and SVG documents can also embed other XML contents. Various different SVG graphics can be conveniently combined to constitute a new SVG graphics [6]. Features of SVG can be summarized as strong interaction, text independence, vector-based graphics, super color control, based on the XML.

Based on the above features, SVG can perfectly display vector graphics in WebGIS. Implementation of WebGIS by using SVG technology has many unique advantages. There are a lot of cases of the research and application of WebGIS based on SVG, such as the preliminary exploration of the solution of WebGIS based on SVG technology [9], and the research on WebGIS design model based on SVG [10].

In this paper, we perform a comparative study on the performance of both SVG and Flash in WebGIS graphics displaying to investigate the format selection of the WebGIS in vector map publishing. 


\section{COMPARISON OF PERFORMANCE OF SVG AND FLASH IN VECTOR WEBGIS GRAPHICS DISPLAY}

This paper compared the performance of SVG and Flash from the following aspects:basic characteristics, data storage, speed of rendering and interactivity.

\section{A. Comparison of Basic Characteristics of SVG and SWF}

The basic comparison of SVG and SWF is shown in table 1. It can be seen from the table that SVG has many features similar to Flash, both of which have rich graphical display functions. The difference between them mainly exhibits in the standard open degree and the support to browser. Because SVG is W3C's standards, and it is relatively open. Flash SWF also discloses the file format specification, but because it is a binary storage, its analysis is relatively complex. In the aspects of browser supporting, a plugin needs to be installed to demonstrate Flash SWF. For the non-HTML5 browser, plugin needs to be installed too to demonstrate SVG. In conclusion, they have little difference in basic characteristics.

TABLE I .COMPARISON OF BASIC CHARACTERISTICS OF SVG AND SWF

\begin{tabular}{|c|c|c|}
\hline $\begin{array}{c}\text { Comparison } \\
\text { contents }\end{array}$ & SVG & SWF \\
\hline Open source & Open & Not completely open \\
\hline Data format & \begin{tabular}{|l} 
Text based on \\
grammar
\end{tabular} & Binary \\
\hline $\begin{array}{c}\text { Stream file } \\
\text { format }\end{array}$ & Non-stream file & Stream file \\
\hline Interactivity & $\begin{array}{l}\text { Script(javascript),SMIL } \\
\text { and event }\end{array}$ & $\begin{array}{l}\text { Script (javascript } \\
\text { /actionscript) and event }\end{array}$ \\
\hline $\begin{array}{l}\text { Graphic } \\
\text { sequence }\end{array}$ & $\begin{array}{l}\text { According to the order of } \\
\text { SVG DOM, the displayed } \\
\text { elements will cover the } \\
\text { front element, but it can be } \\
\text { adjusted by operating the } \\
\text { DOM tree. }\end{array}$ & $\begin{array}{l}\text { Introduce concept of graph } \\
\text { depth. The depth with } \\
\text { maximum value at the top, } \\
\text { it can also be controlled by } \\
\text { script. }\end{array}$ \\
\hline \begin{tabular}{|c|}
$\begin{array}{c}\text { Compaction } \\
\text { algorithm }\end{array}$ \\
\end{tabular} & GZIB & ZLIB \\
\hline $\begin{array}{l}\text { Browser } \\
\text { support }\end{array}$ & $\begin{array}{l}\text { Browsers that support } \\
\text { HTML5 }\end{array}$ & $\begin{array}{l}\text { Not supported, but the } \\
\text { Flash Player plugin can run } \\
\text { in almost each machine, } \\
\text { because the Flash player is } \\
\text { bound in the mainstream } \\
\text { browser }\end{array}$ \\
\hline $\begin{array}{l}\text { transformatio } \\
\text { n support }\end{array}$ & Professional and rich & Professional and rich \\
\hline
\end{tabular}

B. Comparison of Data Storage

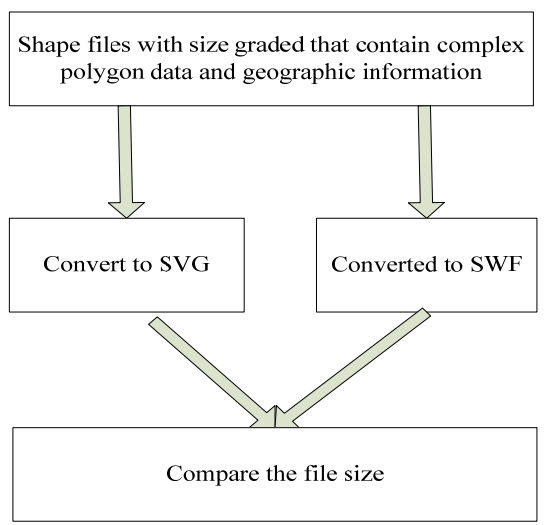

FIGURE I. THE FLOW CHART OF COMPARISON OF FILE SIZES

In aspect of data storage, for the file size of data storage, we will transform the map data of a same pair of ESRI Shape into SWF and SVG format file for convenient comparison. The experiment adopted Shape vector file contained vector polygon data with attribute geographic information. In order to reflect universality in comparison, the file size was graded. The experimental data file sizes were divided into five levels of $0 \sim 1 \mathrm{M}, 1 \sim 5 \mathrm{M}, 5 \sim 10 \mathrm{M}, 10 \sim 20 \mathrm{M}$ and 20M 30M. For each level, we selected representative data. The experimental procedure was shown in figure 1.

The experimental data table records are shown in table 2 . As can be seen from the table, the file size of the SWF format map was generally less than that of the SVG format map file under the condition of expressing the same geographic information. The differences of file size of SWF format file under conditions of filling color and no filling color were large, but that is not the case for SVG. W3C criteria support compression of SVG file by using the gzip compression technology, and the compressed file was called SVGZ, which is essentially an zip file. It has a higher compression ratio compared to that of the original file, and the compressed file size is even smaller than that of the SWF format file.

TABLE II. THE Size OF THE FILE IN CONVERTING THE SHAPE FoRMAT TO SVG AND FLASH

\begin{tabular}{|c|l|l|l|l|l|}
\hline Size level of file(MB) & $\mathbf{0 \sim 1}$ & $\mathbf{1} \sim \mathbf{5}$ & $\mathbf{5} \mathbf{1 0}$ & $\mathbf{1 0 \sim 2 0}$ & $\mathbf{2 0 ~ 3 0}$ \\
\hline Original size of test file(KB) & 323 & 4475 & 8739 & 17773 & 27483 \\
\hline Converted to SVG size(KB) & 578.5 & 1825 & 3788 & 7469 & 8787 \\
\hline $\begin{array}{c}\text { Compressed in SVGZ } \\
\text { format size(KB) }\end{array}$ & 47 & 137 & 284 & 336 & 643 \\
\hline $\begin{array}{c}\text { Converted to SWF(no color } \\
\text { filling) size(KB) }\end{array}$ & 43 & 829 & 1587 & 1072 & 3451 \\
\hline $\begin{array}{c}\text { Converted to SWF(with } \\
\text { color filling) size(KB) }\end{array}$ & 85 & 1404 & 2657 & 2027 & 5644 \\
\hline
\end{tabular}

\section{Page Rendering Speed}

The rendering speed is the displaying speed to open the browser to access to a map, which plays an important role in the user's browsing experience. In order to test and compare the rendering speed of SVG and Flash in the Web browser, we wrote a program based on Web and did the experiments. 
For experimental data, we still use the above map file. The data of each group was done 5 experiments, and the results took the average value of 5 times.

The specific detection method is through the Firefox debugging tools to realtime monitor loading time of each resource. The total time of rending was from the client initiated the request to the server response data and fully displayed on the client. The experimental process was shown in figure 2 .

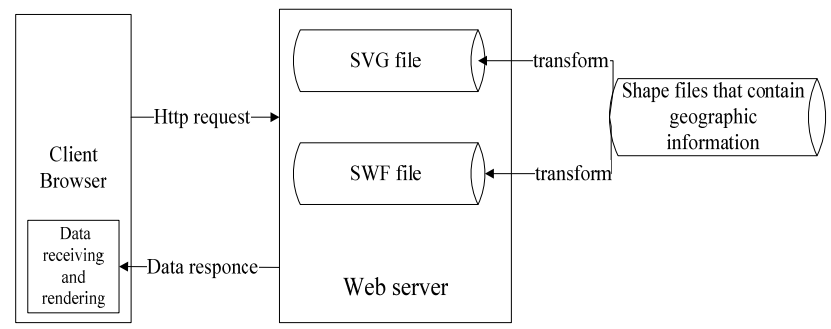

FIGURE II. THE EXPERIMENTAL PROCESS OF RENDERING PERFORMANCE

TABLE III. The Comparison of Page RendeRING SPEed of SVG AND SWF

\begin{tabular}{|c|l|l|l|l|l|}
\hline Size level of file(MB) & $\mathbf{0} \sim \mathbf{1}$ & $\mathbf{1} \sim \mathbf{5}$ & $\mathbf{5} \sim \mathbf{1 0}$ & $\mathbf{1 0} \mathbf{2 0}$ & $\mathbf{2 0} \mathbf{3 0}$ \\
\hline SVG rendering time(s) & 0.03 & 0.66 & 2.14 & 2.75 & 6.55 \\
\hline $\begin{array}{c}\text { SWF rendering time } \\
\text { without color filling(s) }\end{array}$ & 0.006 & 0.61 & 1.01 & 0.36 & 2.92 \\
\hline $\begin{array}{c}\text { SWF rendering time with } \\
\text { color filling(s) }\end{array}$ & 0.006 & 0.72 & 1.69 & 1.12 & 5.42 \\
\hline
\end{tabular}

The experimental results were shown in table 3 . As can be seen from the table, under the same expression of the geographic information, the average rending time of SVG was greater than that of the smaller volume SWF, because the SVG file storage size was larger. This time gap was mainly spent on reading data and network transmission. For large SVG files, this process is time-consuming. When loading data in the network, time-consuming was different due to the limitation of network band width. In addition, for the SWF file with polygon data color filling map, because the file size was greater than that of the SWF unfilled with color, the increase of the rendering speed with the increase of the size was significantly larger than that of the SWF file without color filling. For SVG, it will not appear this kind of circumstance.

\section{Interactive Comparison}

Flash can conveniently establish interaction between the user and graphics by using the ActionScript script. Other interaction of Web elements could be achieved by the communication mechanism between ActionScript and JavaScript, so it can be integrated with the Web page very well. For SVG, it can be fully integrated into the Web page because SVG is a subset of XML, operation of elements can be conducted by Javascript. All the elements of Web page can also be used in SVG, even application of Cascading Style Sheets (CSS), Dynamic HTML (DHTML), Virtual Reality Modeling Language (VRML), Document Object Model (DOM), EXtensible Stylesheet Language (XSL), JavaScript and other various W3C standards. This kind of seamless provided great convenience for the dynamic creation of graphics. With the fully support of HTML5 on SVG, it even can directly use SVG tags in the Web page, browsers that support HTML5 can automatically resolve SVG elements without plugin.

\section{CONCLUSION}

This paper conducted a comparative analysis on the performance of SVG and Flash in visualizing the WebGIS vector graphics from aspects of basic characteristics, file storage, page rendering speed and interactivity. From this analysis, it was revealed that both SVG and Flash could be used for vector graphics displaying in WebGIS application. They achieve similar functions, but have different characteristics. Now, with the development of HTML5 technology and its fully support on SVG, the application of SVG in WebGIS will increases gradually. At the same time, Flash will not easily fall behind because of the advantages of Flash in graphic showing performance and support from Business Companies.

SVG is based on XML with advantages in data exchange, transmission, integration and interoperability and other aspects. The modification is convenient, and the production cost is lower than SWF which is based on the binary coded. Flash has higher data compression rate and rendering speed by using its long term advantages in the network animation. Based on the results of the above comparison, the following suggestions were put forward in the selection and application of vector data based WebGIS in the future:

(1) When the map of WebGIS needs to be modified, the SVG technology is superior to that of Flash technology.

(2) If the realtime transmission and rendering requirements are high and vector map need not to be updated frequently, Flash technology can be used; If the vector map is indeed to be updated frequently but also have certain requirements for the transmission and rendering, SVG is a good choice. We can just compress SVG into a SVGZ to reduce the amount of data transferred in network, then, for the client, decompression and rendering can be used.

(3) If confidentiality and security of vector map data are emphasized, Flash is recommended. The user is very difficult to get the original data information because the Flash SWF file is compiled binary file.

\section{ACKNOWLEDGEMENTS}

This study was financially supported by the Natural Science Foundation of Guangdong Province, China (grant no. S2013010014097 and grant no. S2013040016473).

\section{REFERENCES}

[1] Emanuele Intrieri, Giovanni Gigli, Francesco Mugnai et al., Design and implementation of a landslide early warning system, Engineering Geology, Vol.147-148, page124-136, 2012.

[2] Xianfang, Xing, Yumei, Sun, Zhu, Wang,Gang, Liu, Design and Research on the Expert System for Agricultural Production Management System Based on WebGIS, Chinese Agricultural Science Bulletin, 24, 454-457, 2008.[In Chinese.]

[3] ZHANG Jinqu, ZHU YunQiang, WANG Juanle et al., Flash based WebGIS System and its Application in Monitoring and Evaluating China's Regional Development, International Journal of Digital Content Technology and its Applications 5 (5): 285-295, 2011.

[4] Zhang, X. \& Pazner, M., The icon image map technique for multivariate 
geospatial data visualization: approach and software system, Cartography and Geographic Information Science, 31 (1): 29-41., 2004.

[5] Jinqu, Zhang, Kaiyong, Wang \& Yunpeng, Wang, Visual Associated Analysis with Three Module in One View for Statistical Data, 38, 258260, 2012.[In Chinese.]

[6] Antoniou, V., and J. Morley. , "Web Mapping and Webgis: Do We Actually Need to Use SVG?” In SVG Open 2008: $6^{\text {th }}$ International Conference on Scalable Vector Graphics, Nuremberg, August 26-28, 114, 2008.

[7] Zongzhi, Li, Jun, Sang \& Chunlin, Ran, Development of WebGIS Based on Flash, Computer Applications, 23, 54-56, 2003. [In Chinese.]

[8] Ying Wen, Design and implementation of WebGIS system based on flash, Software Engineering and Service Science, 5, 579 - 582, 2013.

[9] Haosheng Huang, Yan Li, Georg Gartner \& Yunpeng Wang, An SVGbased method to support spatial analysis in XML/GML/SVG-based WebGIS, International Journal of Geographical Information Science, 25(10), 1561-1574, 2011.

[10] Wanggong, Yang \& Jinu, Chen, Research of WebGIS design model based on SVG , Journal of Chongqing University of Posts and Telecommunications (Natural Science Edition), 20, 582-585, 2008.[In Chinese.] 